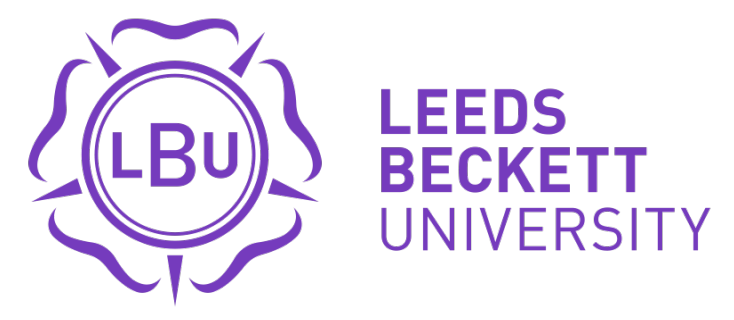

Citation:

Wass, J and Mernagh, D and Pollard, B and Stewart, P and Fox, W and Parmar, N and Jones, B and Kilduff, $L$ and Turner, AN (2019) A comparison of match demands using ball-in-play vs. whole match data in elite male youth soccer players. Science and Medicine in Football. ISSN 2473-3938 DOI: https://doi.org/10.1080/24733938.2019.1682183

Link to Leeds Beckett Repository record:

https://eprints.leedsbeckett.ac.uk/id/eprint/6449/

Document Version:

Article (Accepted Version)

This is an Accepted Manuscript of an article published by Taylor \& Francis in Science and Medicine in Football on 18 October 2019, available online: http://www.tandfonline.com/10.1080/24733938.2019.1682183

The aim of the Leeds Beckett Repository is to provide open access to our research, as required by funder policies and permitted by publishers and copyright law.

The Leeds Beckett repository holds a wide range of publications, each of which has been checked for copyright and the relevant embargo period has been applied by the Research Services team.

We operate on a standard take-down policy. If you are the author or publisher of an output and you would like it removed from the repository, please contact us and we will investigate on a case-by-case basis.

Each thesis in the repository has been cleared where necessary by the author for third party copyright. If you would like a thesis to be removed from the repository or believe there is an issue with copyright, please contact us on openaccess@leedsbeckett.ac.uk and we will investigate on a case-by-case basis. 
Publisher: Taylor \& Francis \& Informa UK Limited, trading as Taylor \& Francis Group

Journal: Science and Medicine in Football

DOI: $10.1080 / 24733938.2019 .1682183$

Title: A comparison of match demands using ball-in-play vs. whole match data in elite male youth soccer players

Running title: The ball in play demands of soccer

Keywords: GPS; worst-case scenario; metabolic load; acceleration; deceleration; highspeed running

Authors: Josh Wass ${ }^{1}$, Dylan Mernagh ${ }^{2}$, Ben Pollard ${ }^{3}$, Perry Stewart ${ }^{4}$, Wesley Fox ${ }^{5}$, Nimai Parmar ${ }^{5}$, Ben Jones ${ }^{6,7}$, Liam Kilduff ${ }^{8,9}$, Anthony N. Turner, $\mathrm{PhD}^{5}$

\section{Institutions:}

1. English Institute of Sport, England

2. Queens Park Rangers Football Club, England

3. Saracens RFC, North London, England

4. Arsenal Football Club, England

5. London Sports Institute, Middlesex University, England

6. Leeds Beckett university, England

7. Rugby Football League, England

8. Applied Sport Technology Exercise and Medicine Research Centre (A-STEM), College of Engineering, Swansea University, Swansea, Wales

9. Welsh Institute of Performance Science, College of Engineering, Swansea University, Swansea, Wales

\section{Correspondence:}

Email: a.n.turner@mdx.ac.uk; Tel No: (+44) 7815321922; Address: As per above 


\title{
A comparison of match demands using ball-in-play vs. whole match data in elite male youth soccer players
}

\begin{abstract}
Effective playing time in soccer is typically $<60$ min per game and while players may reposition themselves when the ball is out of play, it is likely the physical demand decreases during this period. Therefore, if this period is included in data when quantifying match demands, it may under-report the physical requirements of soccer players. This study investigated an alternative method for quantifying external workload called ball in play (BiP), which analyses the data excluding stoppages, and thus potentially offers a more insightful analysis of match demands. Whole match demands as typically recorded via GPS, were compared to those based on BiP, and maximum $\mathrm{BiP}$, with the latter representing worst case scenario phases of play. The 25-elite male youth soccer players (age: $17.9 \pm 0.6$ years; height: $174.8 \pm 6.2 \mathrm{~cm}$; body mass: $66.3 \pm$ $8.1 \mathrm{~kg}$ ) who participated in this study were also categorised in to positional groups (defender, midfielder, and forward) to assess differences in positional demands. While no differences were noted based on position, whole match metrics were significantly lower than mean and maximum BiP metrics $(\mathrm{p}<0.05)$. There was also a significant difference for maximum $\mathrm{BiP}$ outputs across different in-play durations, when comparing 30-60 seconds, $60-90$ seconds, and $>90$ seconds. This data allows practitioners to gain a deeper understanding of the physical demands imposed on players and plan sessions using targets that better represent match demands.
\end{abstract}




\section{INTRODUCTION}

Soccer is characterised by brief bouts of high-intensity running interspersed with longer periods of low-intensity activity (Rampini et al., 2007). The game is a-cyclical in nature with the activity and intensity of players' actions being unpredictable (Turner \& Stewart, 2014). Speed and other explosive activities are critical in determining match outcomes i.e., goals scored and assists (Faude et al., 2012), and can also differentiate between playing levels (Ingebrigtsen et al., 2013). Therefore, the importance of quantifying the physical demands of soccer is crucial for directing the training and preparation process, thus facilitating the performance of players and potentially reducing the risk of injuries (Ehrmann et al., 2016).

Methods of measuring a player's external workload (Castellano et al., 2014) have previously included time motion analysis (TMA), inertial measurement units (IMU's) and semi-automated video analysis systems (such as Prozone ${ }^{\mathrm{TM}}$ ). IMU's, often referred to as global positioning systems (GPS), are a satellite-based navigation technology that measures velocity, orientation, and gravitational force through accelerometers and gyroscopes. Such technology has become commonplace within soccer and many other sports. Until 2015, GPS were not permitted during live soccer competitions, meaning that whilst external workloads in training activities were often measured by GPS, matches were commonly tracked using semi-automated video analysis, providing a disparity between training and match data. However, following a rule change by Federation Internationale de Football Association (FIFA), GPS units are now permitted in competitive matches, subject to the agreement of the National Football Association (Law 4; Section 4, electronic performance and tracking systems). This rule change 
allows practitioners to bridge the gap between training and competition, allowing them to better prepare athletes for the demands of the game (Taylor et al., 2017).

The majority of studies in soccer have reported whole match or part match GPS data (Taylor et al., 2017). For example, on average an elite level outfield player will cover between 10-13 km during a match (Bangsbo et al., 2006). Bradley et al., (2013) further reported that during a typical English Premier League match, players stand for $5.6 \%$ of total time, walk $\left(0.7-7.1 \mathrm{~km} \cdot \mathrm{h}^{-1}\right)$ for $60 \%$, jog $\left(7.2-14.3 \mathrm{~km} \cdot \mathrm{h}^{-1}\right) 26 \%$, and perform running $\left(14.4-19.7 \mathrm{~km} \cdot \mathrm{h}^{-1}\right)$, high speed running $\left(19.8-25.1 \mathrm{~km} \cdot \mathrm{h}^{-1}\right)$ and sprinting $\left(>25.1 \mathrm{~km} \cdot \mathrm{h}^{-1}\right)$ for $6 \%, 2 \%$ and $1 \%$ respectively. Low intensity activity represents $85 \%$ of total time, with high intensity runs representing $9 \%$ (with remaining time spent stood still). While this may provide useful information pertaining to the volume of activity, it does not accurately reflect fluctuations in physical, technical, or tactical intensity (Lacome et al., 2016), and subsequently underrepresents the most intense periods during match play (Delaney et al., 2015). Such analysis may lead to players being underprepared for the most demanding and crucial moments of play (Johnston et al., 2014). It is also pertinent to note that the physical activity profile of a player will be dependent on a number of factors including; positional variations (Bangsbo et al., 2006; Bradley et al., 2010), age (Goto et al., 2015), gender (Bradley et al., 2013), implications of fatigue (Bradley et al., 2010; Mohr et al., 2003), situational and tactical factors (Lagos-Peñas et al., 2012), and overall fitness levels (Lovell et al., 2018).

Lagos-Peñas et al., (2012) reported that effective playing time at a European Soccer Championship was $54.4 \pm 4$ minutes per game. While players may reposition when the ball is out of play, it is likely the physical demand decreases during this period. If the 
period when the ball is out of play ( $\sim 35$ minutes) is included in data when quantifying match demands, it may under-report the overall physical demands that players are exposed to. It is therefore proposed that an alternative method for quantifying external workload be adopted, which analyses the data without stoppages in play (ball going out of play, substitutions, goals, and injuries), namely ball in play (BiP) (Pollard et al., 2018). Previous studies have documented BiP time in elite male and female population, using a semi-automatic multi-camera system (Hill-Haas et al., 2011; Martinez-Lagunas, 2014). Through this analysis, it was found that the average BiP time in over 300 matches was 57.5 minutes. Unfortunately, however, neither study provided objective data to the physical demands during that time period.

Finally, coaches are often interested in preparing athletes for "worst case scenarios (WCS)" (Pollard et al., 2018), which represent the most intense periods of play and are naturally underreported when using averages. If the physical capacity of a player is not sufficient to cope with these demands, then performance is likely to suffer. Training drills can be devised to supersede these, thus ensuring an adequate stimulus is provided and players enter competitive matches able to tolerate these passages. Output targets, such as distance covered and number of sprints for example, that replicate WCS, can be directly determined by quantifying these metrics through the highest scores attained during $\mathrm{BiP}$ analysis, i.e., reporting outputs for maximum rather than average BiP. Furthermore, given intensity is likely time dependent, it is advised to define maximum BiP under the following durations of play: 30-60 seconds, $60-90$ seconds and $>90$ seconds (Pollard et al., 2018), again ensuring the capability to devise training that targets specific passages of WCS play. 
Therefore, the aim of this study was to compare and contrast the demands of elite youth soccer players based on whole match, average, and maximum BiP. Furthermore, given the influence of playing position on physical demand, this study also sought to identify differences attained between forwards, midfielders and defenders, which may become equally apparent when investigating ball out of ball (BoP), given the varying requirements for repositioning. It was hypothesised that mean $\mathrm{BiP}$ and maximum $\mathrm{BiP}$ demands will significantly differ from whole match demands and that outputs will be influenced by playing position. Finally, outputs for maximum BiP would differ based on the duration of play.

\section{METHODS}

\section{Participants}

Data were collected between July-November 2017, during which seven U18 Professional Development League matches were analysed. A total of 25 academy soccer players (age: $17.9 \pm 0.6$ years; height: $174.8 \pm 6.2 \mathrm{~m}$; body mass: $66.3 \pm 8.1 \mathrm{~kg}$ ) took part in the study. Participants were signed to a full-time scholarship at a Category 2 academy and as part of this were required to complete a full-time training program including technical, tactical and physical programs. Typically this comprised of 4 pitch sessions, two gym sessions, and one match per week. Each game only included data from those players who played at least $60 \mathrm{~min}$. This game duration threshold was chosen as it has been shown that substitutes have higher outputs than starting players, potentially due to pacing strategies (Lacome et al., 2016). Selection for fixtures was undertaken by the head age group coach and subjects took part in an average of $2.6 \pm$ 1.5 fixtures $($ Defenders $=2.6 \pm 1.7$, Midfielders $=2.8 \pm 1.6$, Forwards $=2.5 \pm 1$ ) 
Research approval was granted from the institutional ethics committee and the study conformed to the recommendation of the Declaration of Helsinki.

\section{Procedures}

The GPS units were placed in bespoke pockets in the players' match shirts, between their shoulder blades close to their thoracic spine minimising movement artefacts (Harley et al., 2010). The GPS units sampled at $18 \mathrm{~Hz}$ and the accelerometers at $100 \mathrm{~Hz}$ (APEX Pod, STATSports, Belfast, UK), and collected data from four satellite signals. There is a paucity of research into the reliability of the $18 \mathrm{~Hz}$ GPS unit. However, $10 \mathrm{~Hz}$ units have previously been shown to be reliable when assessing team sport movement patterns (Varley et al., 2012) and the manufacturer of these specific units have been utilised for other elite rugby and soccer studies analysing acceleration profiles (Pollard et al., 2018). A list of the analysed dependent variables can be seen in Table 1 and were chosen based on previous research (Pollard et al, 2018). A timeline of all the duration of all plays was generated by SportsCode (SportsCode, Sportstec, Lower Hutt, New Zealand) to define the independent variables $\mathrm{BiP}, \mathrm{BoP}$, and maximum $\mathrm{BiP}$ (referred to now as WCS). BiP is the duration with which play is ongoing prior to the ball exiting the pitch or the referee stopping play. BoP is the duration with which the play ceases due to the ball exiting the pitch or the referee stopping play, and prior to the play starting again. WCS represents the maximum output that occurs during periods $30-60$ seconds, 60-90 seconds and $>90$ seconds (Pollard et al., 2018).

*** INSERT TABLE 1 ABOUT HERE *** 
The GPS units were turned on approximately 2-hours prior to kick-off to gain the necessary signal. The data were then downloaded using the appropriate software (APEX PSA Software, Version 2.6.1.176, STATSports, Belfast, UK) and time periods were split manually for the whole match period. SportsCode generated a timeline of the game (SportsCode, Sportstec, Lower Hutt, New Zealand) and was then integrated into the software to automatically split the match data into periods of BiP, BoP and WCS. Data were then exported into Microsoft Excel (Microsoft Corporation, USA) to transfer the SportsCode generated timeline into BiP durations.

\section{Statistical Analysis}

SPSS (version 24, Chicago, IL, USA) was used to run a linear mixed models analysis, in which the independent variables (BiP, BoP, and WCS derived GPS metrics) were compared with each other, as well as assessing for any interaction effects once players were grouped based on playing position (i.e., defender, midfielder, and forward). Furthermore, interaction effects were also examined across different durations of WCS $(30-60 \mathrm{~s}, 60-90 \mathrm{~s}$, and $>90 \mathrm{~s})$. Bonferroni correction was used for post hoc analysis, and where sphericity was violated, the Greenhouse-Geisser correction was used. The level of significance was set as $p<0.05$ and effect sizes reported via partial eta squared.

\section{RESULTS}

There was a significant difference in mean $\mathrm{m} / \mathrm{min}^{-1}$ across whole match, BiP, BoP and WCS for all metrics. $\mathrm{M} \cdot \mathrm{min}^{-1}\left(\mathrm{~F}(3,66)=1238.32 ; \mathrm{p}<0.01\right.$; partial $\left.\mathrm{n}^{2}=0.98\right)$, mean High Speed Running Per Minute $\left(\operatorname{HSR} \cdot \mathrm{min}^{-1}\right)\left(\mathrm{F}(3,66)=205.19 ; \mathrm{p}<0.01\right.$; partial $\mathrm{n}^{2}=$ $0.934)$, mean acc $\cdot \min ^{-1}\left(\mathrm{~F}(3,66)=170.34 ; \mathrm{p}<0.01 ;\right.$ partial $\left.\mathrm{n}^{2}=0.89\right)$, mean dec $\cdot \mathrm{min}^{-1}$ 
$\left(\mathrm{F}(3,66)=18.45 \mathrm{p}<0.01\right.$; partial $\left.\mathrm{n}^{2}=0.46\right)$, and mean High Metabolic Load Per Minute $\left(\mathrm{HML} \cdot \mathrm{min}^{-1}\right)\left(\mathrm{F}(3,66)=379.37 ; \mathrm{p}<0.01\right.$; partial $\left.\mathrm{n}^{2}=0.95\right)$ presented significant differences across whole match, mean BiP, mean BoP, WCS, and each individual position. All differences across position, whole match, mean BiP, mean BoP, and WCS, as identified by Bonferroni adjusted post hoc analyses, are reported in Table 2.

There was a significant difference for WCS across all metrics: maximum $\mathrm{m} \cdot \mathrm{min}^{-1}(\mathrm{~F}$ $(2,48)=44.64 ; \mathrm{p}<0.01 ;$ partial $\left.\mathrm{n}^{2}=0.650\right), \mathrm{HSR} \cdot \min ^{-1}(\mathrm{~F}(2,48)=71.07 ; \mathrm{p}<0.01$; partial $\left.n^{2}=0.748\right)$, maximum acc $\cdot \min -1\left(F(2,48)=50.43 ; p<0.01 ;\right.$ partial $\left.n^{2}=0.678\right)$, maximum dec $\cdot \min ^{-1}\left(\mathrm{~F}(2,48)=63.68 \mathrm{p}<0.01 ;\right.$ partial $\left.\mathrm{n}^{2}=0.726\right)$, and maximum HML $\cdot \min ^{-1}\left(\mathrm{~F}(2,48)=92.66 ; \mathrm{p}<0.01 ;\right.$ partial $\left.\mathrm{n}^{2}=0.794\right)$ revealed that WCS for $30-60$ seconds, 60-90 seconds and $>90$ seconds were all significantly different. No significant differences between positions were noted. All differences across position, whole match, mean BiP, mean BoP and WCS as identified by Bonferroni adjusted post hoc analyses, are reported in Table 2.

*** INSERT TABLES 2-3 ABOUT HERE ***

\section{DISCUSSION}

The aim of the present study was to analyse both mean and maximum $\mathrm{BiP}$ demands for elite youth soccer players. The results of this study show that there are significant differences between all methods of analysis (whole match, mean BiP, mean BoP and maximum BiP) and across all metrics $\left(\mathrm{m} \cdot \mathrm{min}^{-1}, \mathrm{HSR} \cdot \mathrm{min}^{-1}, \mathrm{Acc} \cdot \mathrm{min}^{-1}, \mathrm{Dec} \cdot \mathrm{min}^{-1}\right.$ and 
HML $\cdot \min ^{-1}$ ) (Table 2). As hypothesised, the metrics for mean BiP were significantly higher than the metrics for mean whole match. Furthermore, the metrics for maximum BiP were significantly higher than metrics for mean $\mathrm{BiP}$ and whole match, thus representing WCS phases of play. However, in contrast to our hypothesis, and with the exception of mean $\mathrm{BiP} \mathrm{m} / \mathrm{min}$, there were no significant differences between the positional groups (defenders, midfielders and forwards).

Mean and maximum BiP offer a novel insight into the demands of elite youth soccer, when compared with whole match averages that have tended to be reported in previous papers (Abbott et al., 2018). Relative to whole match demands, these metrics may allow for a more valid marker of training intensity, and allow practitioners to work in line with the training principles of specificity, progressive overload, and individuality. By understanding these physical demands and how to manipulate training drills to achieve them in practice, the practitioner can be more effective in objectively planning and evaluating macro and microcycles, thus facilitating more appropriate internal training loads, which drive adaptations better suited to the demands of match play. Although there is a significant difference between all metrics, it would appear that the largest differences were between the metrics HSR, accelerations, and decelerations. This information could be used to adapt practice accordingly and ensure adequate exposure to each physical component, in line with match demands. For example, greater utilisation or large open spaces or transitional games to elicit longer sprints, and smallsided games to elicit more accelerations and decelerations. Furthermore, maximum BiP may provide a more valid measure of session intensity for conditioning drills, or as part of an individual return to play criteria to ensure the appropriate physical capacity is being developed and attained. 
The discrete maximum BiP periods (30-60 seconds, 60-90 seconds and $>90$ seconds) offer greater insight still, in to the development of match demands for fitness. The peak output for all metrics occurred during maximum plays between $30-60$ s, and the lowest outputs occurred during plays that lasted over 90 seconds; the decrease in physical output (or work done) as time increases, is most likely due to fatigue (Yiannakos and Armatas, 2006). If the purpose of conditioning is to prepare athletes for WCS during competitive fixtures, then the desired GPS outputs should be dependent on the length of the drill e.g. drills between 30-60 seconds should have higher relative outputs than drills over 90 seconds. In summary, therefore, maximum BiP offers a more microscopic view of shorter high intensity periods of play that can aid session design, helping planning towards game constraints such as numbers of players (Harley et al., 2010), pitch dimensions (Olthof et al., 2018), and number of touches (Little and Williams, 2007).

Regarding playing position, Pollard et al. (2018) found significant differences between positional groups, primarily between HSR, HMLD, and collisions. In contrast, the present study shows that except for BiP $\mathrm{m} \cdot \mathrm{min}^{-1}$, no significant differences were found between positional groups. Anecdotally, this could be due to the broad positional groups used: defender, midfielder, and forward, based on a typical 4-3-3 formation. Previous research into match demands of soccer have used discrete positional roles: centre back, full back, centre midfield, wide forward, and centre forward (Abbott et al., 2018). Similarly, Baptista et al., (2018) divided players up in to central backs, full-backs, central midfielders, wide midfielders, and central forwards. This split led to the finding that central backs and central midfielders had significantly $(\mathrm{p}<0.001)$ lower work-rate in sprints, decelerations and accelerations than full-backs, wide midfielders and central forwards. Also, that wide midfielders and full-backs performed significantly more turns 
$\left(>90^{\circ}\right)$ than central backs. Using these playing position (with more emphasis on central vs. laterally positioned players) may have allowed greater insight into match demand differences between positional groups, conforming to the more modern format of the game. However, analysing data with respect to several discrete positions usually calls for a sample size that is not available within most professional clubs. As such, future research into $\mathrm{BiP}$ match demands should investigate the use of discrete roles, as well as across different formations, phases of play (i.e., attacking, defending, transition to attack, and transition to defend) and styles of play (e.g., high-press and counter-attack).

\section{PRACTICAL APPLICATIONS}

This study is the first to report whole match, BiP, BoP and WCS demands of elite youth soccer players. BiP analysis allows an accurate representation of game demands, which allow for a deeper understanding in to the physical demands imposed on elite youth soccer players. By gaining a greater understanding of typical, but perhaps more so, the max demands of duration specific movement in elite youth soccer players, training can be designed to match or supersede these metrics whilst monitored by GPS for feedback. By using this method of analysis, there is likely going to be a greater amount of relevant physical load experienced, allowing a greater transfer to performance in match play. This increase in relevant physical load may help sports scientists and coaches balance a required increase in intensity with the management of fatigue, facilitated by a reduction in unnecessary training, once thought to promote match fitness. This extends to ensuring GPS outputs are dependent on the length of the drill in accordance with BiP demands. Coupling this with increased synchronicity of the technical and tactical demands, within the four phases of the game, allows players to execute skills and decision making at intensities above game speed which will ultimately aid in 
performance.

\section{REFERENCES}

1. Abbott W, Brickley G, and Smeeton, N. An individual approach to monitoring locomotive training load in English Premier League academy soccer players. Int J Sports Sci Coach 13: 421-428, 2018.

2. Baptista, I, Johansen, D, Seabra, A, and Pettersen, SA. Position specific player load during match-play in a professional football club. PloS one 13.5 e0198115, 2018.

3. Bangsbo J, Mohr M, and Krustrup P. Physical and metabolic demands of training and match-play in the elite football player. J Sports Sci 24: 665-674, 2006.

4. Bradley P, Carling C, Diaz A, Hood P, Barnes C, Ade J, and Mohr M. Match performance and physical capacity of players in the top three competitive standards of English professional soccer. Human Move Sci 32: 808-821, 2013.

5. Bradley P, Di Mascio M, Peart D, Olsen P, and Sheldon B. High-intensity activity profiles of elite soccer players at different performance levels. $J$ Strength Cond Res 24: 2343-2351, 2010.

6. Castellano J, Alvarez-Pastor D, and Bradley P. Evaluation of research using computerised tracking systems (Amisco ${ }^{\circledR}$ and Prozone ${ }^{\circledR}$ ) to analyse physical performance in elite soccer: A systematic review. Sports Med 44: 701-712, 2014.

7. Chambers R, Gabbett T, Cole M, and Beard A. The use of wearable microsensors to quantify sport-specific movements. Sports Med 45: 1065-1081, 2015.

8. Delaney J, Scott T, Thornton H, Bennett K, Gay D, Duthie G, and Dascombe B Establishing duration-specific running intensities from match-play analysis in rugby league. Int J Sports Physiol Perform 10: 725-731, 2015.

9. Ehrmann F, Duncan C, Sindhusake D, Franzsen W, and Greene D. GPS and injury prevention in professional soccer. J Strength Cond Res 30: 360-367, 2016.

10. Faude O, Koch T, and Meyer T. Straight sprinting is the most frequent action in goal situations in professional football. J Sports Sci 30: 625-631, 2012. 
11. Goto H, Morris J, and Nevill M. Match analysis of U9 and U10 English premier league academy soccer players using a global positioning system: Relevance for talent identification and development. J Strength Cond Res 29: 954-963, 2015.

12. Hamilton H. Ball (not) in play: Effective time in football. Soccermetrics. Retrieved from http://www.soccermetrics.net/team-performanceleffective-timein-football. Accessed 26 June, 2013.

13. Harley J, Barnes C, Portas M, Lovell R, Barrett S, Paul D, and Weston M. Motion analysis of match-play in elite U12 to U16 age-group soccer players. $J$ Sports Sci 28: 1391-1397, 2010.

14. Hill-Haas S, Dawson B, Impellizzeri F, and Coutts A. Physiology of small-sided games training in football. Sports Med 41: 199-220, 2011.

15. Ingebrigtsen J, Shalfawi S, Tønnessen E, Krustrup P, and Holtermann A. Performance effects of 6 weeks of aerobic production training in junior elite soccer players. $J$ Strength Cond Res 27: 1861-1867, 2013.

16. Johnston R, Gabbett T, and Jenkins D. Applied sport science of rugby league. Sports Med 44: 1087-1100, 2014.

17. Lacome M, Piscione J, Hager J, and Carling C. Analysis of running and technical performance in substitute players in international male rugby union competition. Int J Sports Physiol Perform 11: 783-792, 2016.

18. Lacome M, Piscione J, Hager J, and Carling C. Fluctuations in running and skillrelated performance in elite rugby union match-play. Euro J Sports Sci 17: 132143, 2017.

19. Lagos-Peñas C, Rey E, and Lago-Ballesteros J. The influence of effective playing time on physical demands of elite soccer players. Open Sports Sci J 5: 188-92, 2012.

20. Little T, and Williams A. Measures of exercise intensity during soccer training drills with professional soccer players. J Strength Cond Res 21: 367-371, 2007.

21. Lovell T, Bocking C, Fransen J, Kempton T, and Coutts A. Factors affecting physical match activity and skill involvement in youth soccer. Sci Med Football 2: 58-65, 2018.

22. Martinez-Lagunas V, Niessen M, and Hartmann U. Women's football: Player characteristics and demands of the game. J Sport Health Sci 3: 258-272, 2014. 
23. Mohr M, Krustrup P, and Bangsbo J. Match performance of high-standard soccer players with special reference to development of fatigue. J Sports Sci 21: 519-528, 2003.

24. Olthof S, Frencken W, and Lemmink K. A. Match-derived relative pitch area changes the physical and team tactical performance of elite soccer players in small-sided soccer games. J Sports Sci 36: 1557-1563, 2018.

25. Pollard B, Turner A, Eager R, Cunningham D, Cook C, Hogben P, and Kilduff L. The ball in play demands of international rugby union. J Sci Med Sport. (Published ahead of print). doi:10.1016/j.jsams.2018.02.015.

26. Rampinini E, Coutts A, Castagna C, Sassi R, and Impellizzeri F. Variation in top level soccer match performance. Int J Sports Med 28: 1018-1024, 2007.

27. Taylor J, Wright A, Dischiavi S, Townsend M, and Marmon A. Activity demands during multi-directional team sports: a systematic review. Sports Med 47: 2533-2551, 2017.

28. Turner A, and Stewart P. Strength and conditioning for soccer players. Strength Cond J 36: 1-13, 2014.

29. Varley M, Elias G, and Aughey R. Current match-analysis techniques' underestimation of intense periods of high-velocity running. Int J Sports Physiol Perform 7: 183-185, 2012.

30. Yiannakos, A. and Armatas, V. Evaluation of the goal scoring patterns in European Championship in Portugal 2004. International Journal of Performance Analysis in Sport 6(1): 178-188, 2006. 
Table 1: Analysed metrics and operational descriptions from the GPS units

\begin{tabular}{|l|c|}
\hline Metric & Description \\
\hline Metres Per Minute & $\begin{array}{c}\text { Total distance covered (m) including; walking, jogging, } \\
\text { running \& sprinting/total match duration (minutes) }\end{array}$ \\
\hline $\begin{array}{l}\text { High Metabolic Load } \\
\text { Distance Per Minute } \\
\text { (HMLD/Min) }\end{array}$ & $\begin{array}{c}\text { Distance accelerating over } 2.5 \mathrm{~m} \mathrm{~s}^{-2} \text { and sprinting over } \\
\text { High Speed Running Per } \\
\text { Minute (HSR/min) }\end{array}$ \\
\hline $\begin{array}{c}\text { Accelerations Per Minute } / \text { total match duration (minutes) } \\
\text { (Acc/min) }\end{array}$ & $\begin{array}{c}\text { Change in velocity over } 3 \mathrm{~m} \mathrm{~s}^{-2} / \text { total match duration } \\
\text { (minutes) }\end{array}$ \\
\hline $\begin{array}{c}\text { Decelerations Per Minute } \\
\text { (Dec/min) }\end{array}$ & $\begin{array}{c}\text { Change in velocity over } 3 \mathrm{~m} \mathrm{~s}^{-2} / \text { total match duration } \\
\text { (minutes) }\end{array}$ \\
\hline
\end{tabular}




\begin{tabular}{|l|c|c|c|c|c|}
\hline & Position & $\begin{array}{c}\text { Whole match } \\
\text { data (Mean) }\end{array}$ & $\begin{array}{c}\text { Ball in play } \\
\text { (Mean) }\end{array}$ & $\begin{array}{c}\text { Ball out of play } \\
\text { (Mean) }\end{array}$ & $\begin{array}{c}\text { Ball in play } \\
\text { (Maximum/WCS) }\end{array}$ \\
\hline
\end{tabular}




\begin{tabular}{|c|c|c|c|c|c|}
\hline \multirow{5}{*}{ 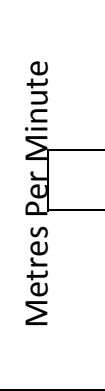 } & Defender & $98.68 \pm 6.28 * \times \infty$ & $\begin{array}{l}119.11 \pm \\
4.95^{\wedge} \beta \times \infty\end{array}$ & $\begin{array}{c}20.44 \pm \\
4.05^{* \wedge} \infty\end{array}$ & $202.42 \pm 30.43^{* \wedge x}$ \\
\hline & Forward & $91.31 \pm 5.6 *_{\mu}$ & $104.48 \pm 5.15^{\wedge} \mu \alpha$ & $13.17 \pm$ & $182.27 \pm 15.35^{* \wedge} \times$ \\
\hline & \begin{tabular}{l|l} 
& Position \\
\end{tabular} & \multicolumn{2}{|c|}{ WCS for plays } & WCS for p4ays ${ }^{* \wedge} \infty$ & WCS for plays \\
\hline & Midfield & $107.8 \pm 6.77^{*} \beta$ & $122.99 \pm 7.89^{\wedge} \beta$ & $15.18 \pm 3.8^{* \wedge \infty}$ & $212.5 \pm 16.42^{* \wedge x}$ \\
\hline & Total & $100.27 \pm 9.26^{*}$ & $116.56 \pm 9.956^{\wedge}$ & $\begin{array}{c}16.30 \pm \\
4.86^{* \wedge} \infty\end{array}$ & $200.93 \pm 25.39 * \wedge x$ \\
\hline \multirow{4}{*}{ 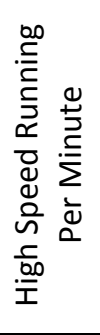 } & Defender & $6.31 \pm 1.96^{*} \times \infty$ & $8.17 \pm 2.10^{\wedge} \times \infty$ & $1.86 \pm 1.49 * \wedge \infty$ & $62.80 \pm 25.02^{* \wedge x}$ \\
\hline & Forward & $7.0 \pm 1.07 * \times \infty$ & $9.67 \pm 1.42^{\wedge} \times \infty$ & $2.68 \pm 1.07^{* \wedge \infty}$ & $61.65 \pm 19.75^{* \wedge x}$ \\
\hline & Midfield & $6.61 \pm 1.3 * \times \infty$ & $8.2 \pm 1.91^{\wedge} \times \infty$ & $1.59 \pm 0.80^{* \wedge \infty}$ & $74.62 \pm 23.3^{* \wedge x}$ \\
\hline & Total & $6.62 \pm 1.46^{*} \times \infty$ & $8.6 \pm 1.9^{\wedge} \times \infty$ & $1.98 \pm 1.17^{* \wedge \infty}$ & $66.88 \pm 23.86^{* \wedge x}$ \\
\hline \multirow{4}{*}{ 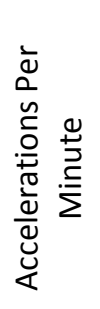 } & Defender & $0.79 \pm 0.2 * \times \infty$ & $1.22 \pm 0.28^{\wedge} \times \infty$ & $0.43 \pm 0.16^{* \wedge \infty}$ & $5.39 \pm 1.39^{* \wedge x}$ \\
\hline & Forward & $0.74 \pm 0.14^{*} \times \infty$ & $1.04 \pm 0.18^{\wedge} \times \infty$ & $0.30 \pm 0.06^{* \wedge \infty}$ & $5.10 \pm 1.52^{* \wedge x}$ \\
\hline & Midfield & $0.71 \pm 0.12 * \times \infty$ & $0.95 \pm 0.17^{\wedge} \times \infty$ & $0.25 \pm 0.09 * \wedge \infty$ & $4.49 \pm 1.77^{* \wedge x}$ \\
\hline & Total & $0.74 \pm 0.15^{*} \times \infty$ & $1.06 \pm 0.24^{\wedge} \times$ & $0.32 \pm 0.14^{* \wedge \infty}$ & $4.98 \pm 1.62^{* \wedge x}$ \\
\hline & Defender & $0.86 \pm 0.26^{*} \times \infty$ & $1.2 \pm 0.32^{\wedge} \times \infty$ & $0.34 \pm 0.1^{* \wedge} \infty$ & $5.05 \pm 1.14^{* \wedge x}$ \\
\hline 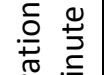 & Forward & $0.81 \pm 0.13^{*} \times \infty$ & $1.11 \pm 0.19^{\wedge} \times \infty$ & $0.31 \pm 0.08^{* \wedge \infty}$ & $5.57 \pm 1.15^{* \wedge x}$ \\
\hline$\frac{0}{\tilde{g}} \sum_{\overline{0}} \sum_{\overline{0}}$ & Midfield & $0.78 \pm 0.11 * \times \infty$ & $1.09 \pm 0.22^{\wedge} \times \infty$ & $0.32 \pm 0.13^{* \wedge \infty}$ & $4.87 \pm 1.15^{* \wedge x}$ \\
\hline & Total & $0.81 \pm 0.17^{*} \times \infty$ & $1.13 \pm 0.24^{\wedge} \times \infty$ & $0.32 \pm .10^{* \wedge} \infty$ & $5.12 \pm 1.18^{* \wedge x}$ \\
\hline & Defender & $19.09 \pm 4.16^{*} \times \infty$ & $26.75 \pm 4.37^{\wedge} \times \infty$ & $7.66 \pm 1.87^{* \wedge \infty}$ & $83.06 \pm 19.19 * \wedge x$ \\
\hline $\bar{\varpi} \nsubseteq$ & Forward & $17.8 \pm 1.3^{*} \times \infty$ & $23.82 \pm 1.9^{\wedge} \times \infty$ & $6.03 \pm 1.74^{* \wedge \infty}$ & $84.11 \pm 17.79 * \wedge x$ \\
\hline$\sum_{i}$ & Midfield & $20.67 \pm 2.68 * \times \infty$ & $26.86 \pm 3.78^{\wedge} \times \infty$ & $6.19 \pm 1.9 * \wedge \infty$ & $91.10 \pm 16.52^{* \wedge x}$ \\
\hline & Total & $19.36 \pm 3.1 * \times \infty$ & $25.97 \pm 3.7^{\wedge} \times \infty$ & $6.61 \pm 1.91^{* \wedge \infty}$ & $86.31 \pm 18.25^{* \wedge x}$ \\
\hline $\begin{array}{l}*=\text { Sigr } \\
\wedge=\text { Sigr } \\
x=\text { Sigr } \\
\infty=\text { Sig } \\
\alpha=\text { Sig } \\
\beta=\operatorname{Sig} \\
\mu=\operatorname{Sig}\end{array}$ & $\begin{array}{l}\text { ficantly differ } \\
\text { ficantly differ } \\
\text { ficantly differ } \\
\text { ificantly diffe } \\
\text { ficantly differ } \\
\text { ficantly differ } \\
\text { ficantly differ }\end{array}$ & $\begin{array}{l}\text { to BiP, } \\
\text { to Whole Match, } \\
\text { to bop, } \\
\text { it to WCS } \\
\text { to Defender } \\
\text { to forward, } \\
t \text { to midfield }\end{array}$ & & & \\
\hline
\end{tabular}

Table 2: Mean data for whole game, ball in play and ball out of play and Max Ball in

Play for all GPS-based metrics.

Table 3: Max Ball in Play for 30-60s, 60-90s and $>90$ s 


\begin{tabular}{|c|c|c|c|c|}
\hline & & $(30-60 s)$ & (60-90s) & (>90s) \\
\hline \multirow{4}{*}{ 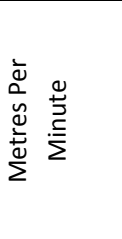 } & Defender & $197.3 \pm 25 z$ & $173.1 \pm 32.1$ & $154.5 \pm 17.2 x$ \\
\hline & Midfield & $212 \pm 20.7 y z$ & $181 \pm 13.8 x$ & $172.8 \pm 16.6 x$ \\
\hline & Forward & $192.4 \pm 25.7 z$ & $163.4 \pm 11.9$ & $145.3 \pm 14.6 x$ \\
\hline & Total & $200.9 \pm 24.4 z$ & $173.2 \pm 23.1$ & $158.2 x$ \\
\hline \multirow{4}{*}{ 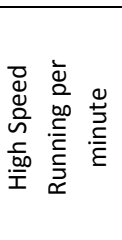 } & Defender & $62.9 \pm 26 y z$ & $31.6 \pm 10.7 x$ & $27.4 \pm 13 x$ \\
\hline & Midfield & $77.6 \pm 25.3 y z$ & $34.7 \pm 12.2 x$ & $31.4 \pm 13.8 x$ \\
\hline & Forward & $65.1 \pm 17.7 y z$ & $34.5 \pm 10.1 x$ & $25.3 \pm 7 x$ \\
\hline & Total & $68.3 \pm 23.6 y z$ & $33.4 \pm 10.7 x$ & $28.2 \pm 11.9 x$ \\
\hline \multirow{4}{*}{ 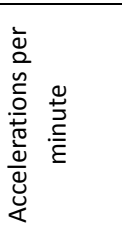 } & Defender & $5.2 \pm 1.5 y z$ & $2.5 \pm 1 x$ & $1.9 \pm 0.9 x$ \\
\hline & Midfield & $4.7 \pm 1.9 z$ & $3.2 \pm 0.8$ & $2 \pm 0.9 x$ \\
\hline & Forward & $4.9 \pm 1.8 z$ & $3.3 \pm 1$ & $2.4 \pm 0.7 x$ \\
\hline & Total & $5 \pm 1.7 z$ & $3 \pm 1$ & $2.1 \pm 0.8 x$ \\
\hline \multirow{4}{*}{ 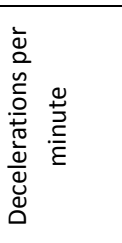 } & Defender & $4.9 \pm 1.2 y z$ & $2.7 \pm 1 x$ & $2.2 \pm 0.9 x$ \\
\hline & Midfield & $5.1 \pm 1.2 \mathrm{yz}$ & $3.5 \pm 1 x$ & $2.6 \pm 0.9 x$ \\
\hline & Forward & $5.6 \pm 1.2 y z$ & $3.7 \pm 1 x$ & $2.4 \pm 0.8 x$ \\
\hline & Total & $5.1 \pm 1.2 y z$ & $3.2 \pm 1 x$ & $2.4 \pm 0.8 x$ \\
\hline \multirow{4}{*}{ 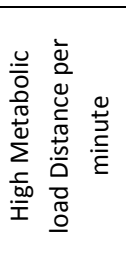 } & Defender & $83.7 \pm 20.4 y z$ & $53.8 \pm 13 x$ & $44.5 \pm 15.7 x$ \\
\hline & Midfield & $91.5 \pm 18.4 y z$ & $61.7 \pm 9.6 x$ & $51.1 \pm 9.3 x$ \\
\hline & Forward & $90.5 \pm 18.6 y z$ & $56.3 \pm 6.2 x$ & $42.5 \pm 7.4 x$ \\
\hline & Total & $88.1 \pm 18.9 y z$ & $57.1 \pm 10.7 x$ & $46.1 \pm 12.1 x$ \\
\hline \multicolumn{5}{|c|}{$\begin{array}{l}x=\text { Significantly different to WCS for plays } 30-60 \mathrm{~s}, \\
y=\text { Significantly different to WCS for plays } 60-90 \mathrm{~s} \\
z=\text { Significantly different to WCS for plays }>90 \mathrm{~s} \\
\infty=\text { Significantly different to WCS } \\
\alpha=\text { Significantly different to Defender } \\
\beta=\text { Significantly different to forward, } \\
\mu=\text { Significantly different to midfield }\end{array}$} \\
\hline
\end{tabular}

